\title{
Neuroendocrine System of the Skin
}

\author{
Andrzej Slominski \\ Department of Pathology and Laboratory Medicine, University of Tennessee Health Science Center, \\ Memphis, Tenn., USA
}

\begin{abstract}
Key Words
Neuroendocrine system, cutaneous - Neuropeptides · Hormones - Neurohormones - Steroids - Secosteroids • Hypothalamic-pituitary-adrenal axis · Serotoninergic/ melatoninergic system - Hypothalamic-pituitarythyroid axis
\end{abstract}

\begin{abstract}
Evidence is accumulating that the skin can serve as a peripheral neuroendocrine organ. The skin neuroendocrine activities are predominantly independent of regulation from the central level (which controls classical hormone secretion) but are rather regulated by local cutaneous factors. These endocrine factors would represent an exquisite regulatory layer addressed at restricting maximally the effect of noxious agents in the skin to preserve local and consequently global homeostasis.
\end{abstract}

Copyright (c) 2005 S. Karger AG, Basel

\section{Introduction}

The strategic location of the skin as the barrier between the environment and the internal milieu determines its critical function in the preservation of body homeostasis [1]. The skin is continuously exposed to many hostile environmental factors and to acute transfers of solar, ther- mal or mechanical energy $[1,2]$. There are several instant mechanisms for restoration of the skin structural and functional integrity upon disruption. Such mechanisms are constituted by the barrier-forming properties of the epidermis, the secretory activity of adnexal structures, skin immune and pigmentary systems as well as by vascular and mesenchymal components of the dermis [1, 39] (fig. 1). Precise coordination of these responses appears to be the function served by local cutaneous neuroendocrine activities [1] (fig. 2, 3). Thus, cutaneous signals relayed to this neuroendocrine system may trigger cascades of responses addressed at maintaining local and hence global homeostasis [1] (fig. 4).

\section{Skin as a Neuroendocrine Organ}

Skin cells produce hormones, neurotransmitters and neuropeptides and corresponding functional receptors [1]. Hormones and neurotransmitters are either produced locally in epidermal, adnexal and dermal cells or released in situ from cutaneous nerve endings [1]. There are also cutaneous exocrine activities performed by the adnexal structures, e.g. eccrine, apocrine and sebaceous glands and hair follicles $[6,9]$. Exocrine activities function to strengthen the epidermal barrier, regulate thermoregulation or to participate in the defense against microorganisms or in social communication [1, 5, 6, 8-10].

\section{KARGER}

(ㄱ) 2005 S. Karger AG, Basel

Fax +41613061234

E-Mail karger@karger.ch

www.karger.com
Accessible online at: www.karger.com/drm
Andrzej Slominski, MD, $\mathrm{PhD}$

Department of Pathology, Suite 599

University of Tennessee Health Science Center, 930 Madison Avenue Memphis, TN 38163 (USA)

Tel. +1 901448 3741, Fax +1 901448 6979, E-Mail aslominski@utmem.edu 
Fig. 1. Organization of the exocrine and endocrine skin units. Reprinted from Slominski and Wortsman [1], with permission from the Endocrine Society (copyright owner).

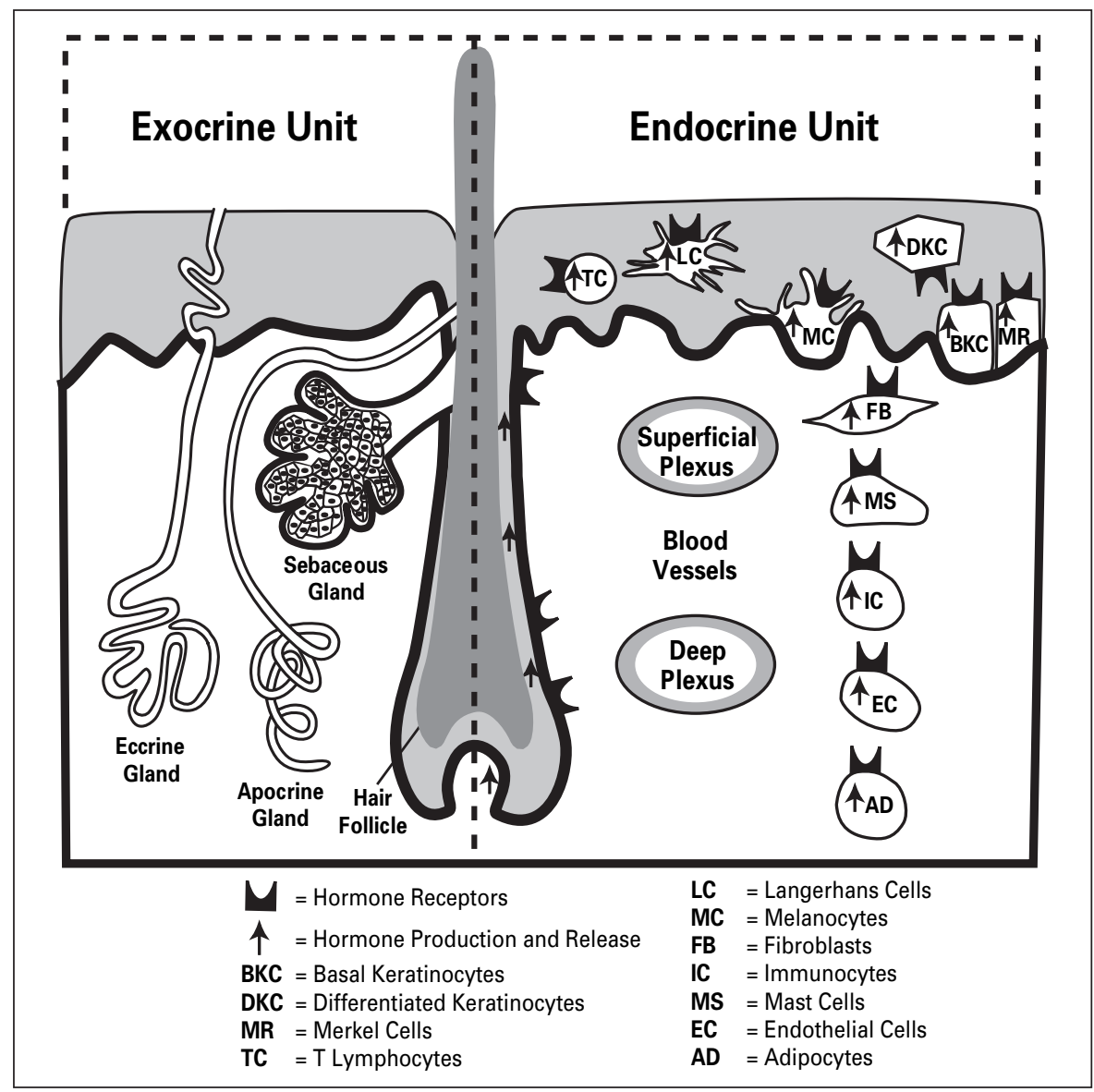

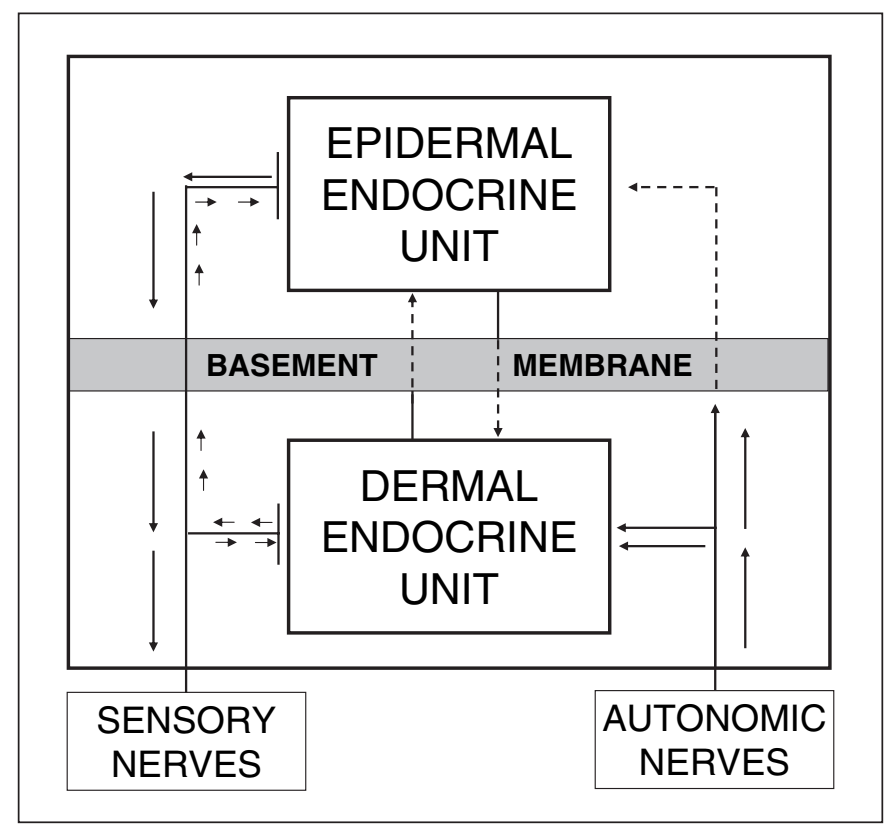

Fig. 2. The proposed flow of information between dermal and epidermal endocrine units and their systemic connections. Reprinted from Slominski and Wortsman [1], with permission from the Endocrine Society (copyright owner).

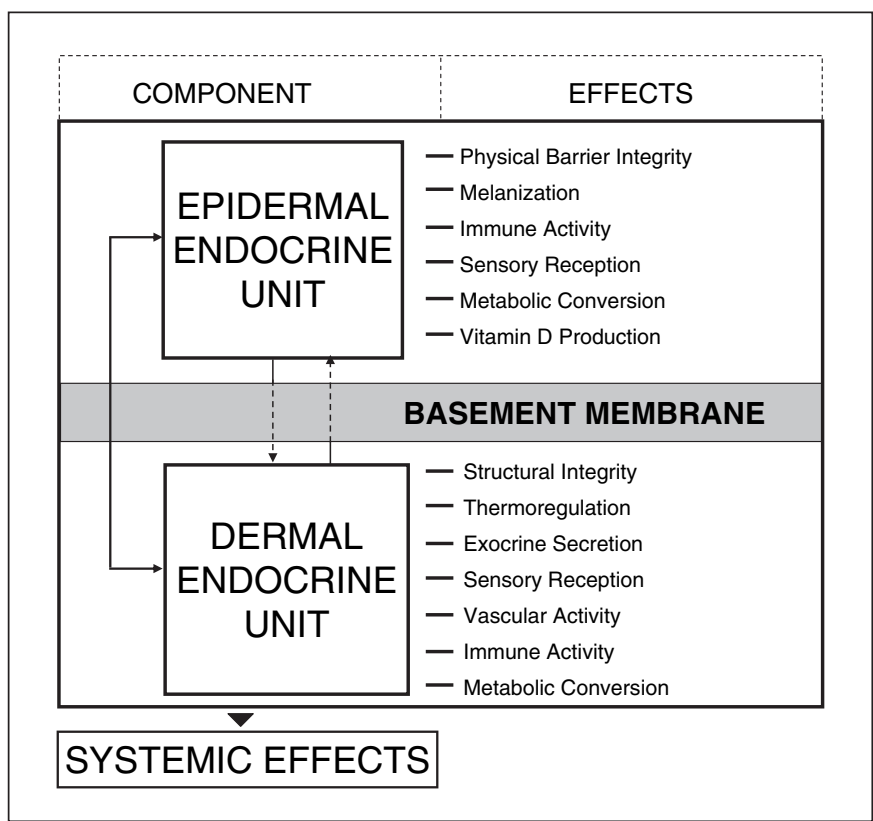

Fig. 3. Organization and function of the skin neuroendocrine system. Reprinted from Slominski and Wortsman [1], with permission from the Endocrine Society (copyright owner). 


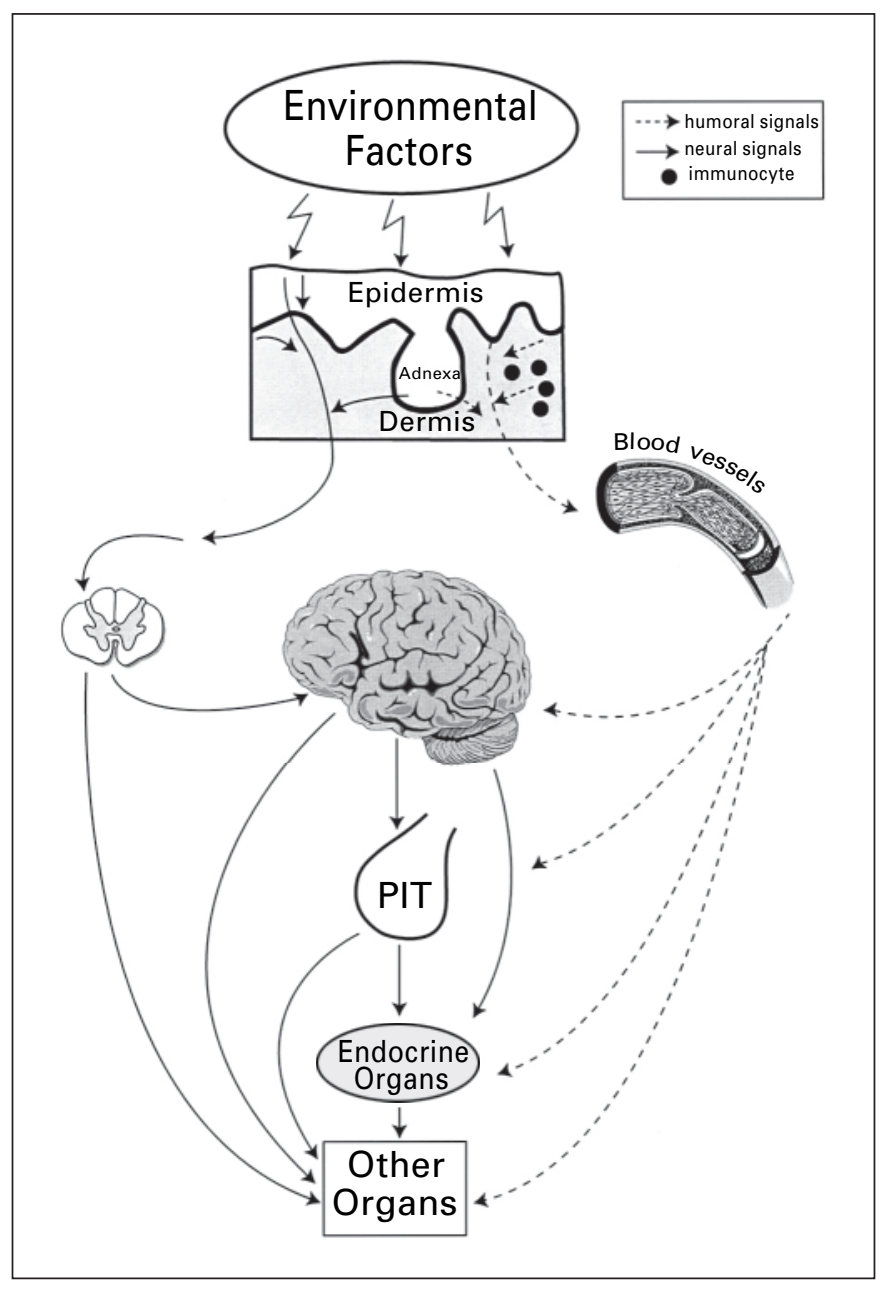

Fig. 4. Systemic effects of the skin neuroendocrine system. PIT = Pituitary. Reprinted from Slominski and Wortsman [1], with permission from the Endocrine Society (copyright owner).

\section{Cutaneous Neuroendocrine Axes}

These activities can be organized into cutaneous neuroendocrine axes [11]. Special attention deserves a cutaneous equivalent of the hypothalamic-pituitary-adrenal (HPA) axis that would regulate local responses to stress independently from the central level [12-16]. Among others are local cholinergic [17, 18], catecholaminergic [19, 20] and serotoninergic/melatoninergic systems [21, 22], the steroidogenic pathway in the skin $[1,23-28]$ and cutaneous expression of the pituitary-thyroid axis elements [29]. Of particular interest is a potential for the skin to express a novel secosteroidogenic pathway of which the organization and role in the regulation of cutaneous homeostasis are the subject of extensive experimental effort [27] (fig. 5).

Cutaneous Neuroendocrine System

\section{Cutaneous HPA Axis}

The main adaptive responses to systemic stress are mediated by the HPA axis [30]. Activation of the HPA system starts with hypothalamic production of corticotropin-releasing hormone $(\mathrm{CRH})$, which in the anterior pituitary activates $\mathrm{CRH}$ receptor type 1 and induces production and release of the proopiomelanocortin (POMC)derived peptides adrenocorticotropin $(\mathrm{ACTH}), \alpha$-melanocyte-stimulating hormone and $\beta$-endorphin [31-33]. ACTH stimulates production and secretion of cortisol (humans) or corticosterone (rodents) by the adrenal cortex; these steroids mount the body response addressed at counteracting the effect of the stressor and suppress the HPA axis through a negative feedback mechanism [3033].

We have demonstrated that the skin expresses a neuroendocrine system using mediators similar to those involved in the classical endocrine systems at the brain and pituitary levels $(\mathrm{CRH}$, urocortin and the POMC-derived peptides $\beta$-endorphin, ACTH and $\alpha$-melanocyte-stimulating hormone) [reviewed in 1, 14, 15, 34-39]. Skin cells also express functional receptors activated by the above neuropeptides $[4,5,7,14,16,34,40,41]$. Therefore, we have proposed that the cutaneous defense against stressors is organized as an equivalent of the HPA axis that operates as coordinator and executor of the local responses to stress [1, 12, 14, 15, 42]. Local effectors of this axis, i.e. CRH, urocortin and POMC peptides, would regulate skin pigmentary, immune, epidermal, dermal and adnexal systems $[5,7,10,14,16,41,43,44]$. Accordingly, exposure to UV light (physical stress) or biological or chemical stress would trigger multiple pathways involving structuralized or simultaneous local production of $\mathrm{CRH}$ and $\mathrm{CRH}$-related peptides and POMC-derived messages [12-14, 42]. Hence, signals generated by the integrated actions of these peptides would counteract the local effects of the stress and also attenuate the attendant cutaneous responses $[1,14]$. This complex response would be susceptible to heterotopic modulation (attenuation) through feedback inhibition by a cortisol/corticosterone. Thus, by analogy with the central axis, stress would stimulate production and secretion of ACTH of cutaneous origin, which would stimulate production and secretion of glucocorticoids - recognized inhibitors of the immune system [42]. Such a mode of action would then represent an evolutionary continuum, where the most optimal response to stress is conserved at both central and peripheral levels [1, 14].

Most recent data from our laboratory have provided experimental support for the above hypothesis [45, 46]. 
Fig. 5. Transformation of 7-DHC (1) to 7DHP (2), followed by a proposed sequence for the enzymatic transformation of 7-DHP to its hydroxyl derivatives (3-10) and/or to secosteroids (11-19) generated by the action of UVB radiation. $3=3 \beta, 11 \alpha$ - or $\beta$-Dihydroxypregna-5,7-dien-20-one; $4=3 \beta, 17 \beta$ dihydroxypregna-5,7-dien-20-one; $5=3 \beta$, 21-dihydroxypregna-5,7-dien-20-one; $6=3 \beta$, $17 \beta, 21$-trihydroxypregna-5,7-dien-20-one; $7=3 \beta, 11 \alpha$ - or $11 \beta, 21$-trihydroxypregna5,7-diene-20-one; $8=3 \beta, 11 \alpha$ - or $11 \beta, 17$-trihydroxypregna-5,7-diene-20-one; $9=3 \beta$, $11 \alpha$ - or $\beta, 17 \beta, 21$-tetrahydroxypregna-5,7dien-20-one; $10=3 \beta, 20 \alpha$ - or $\beta$-dihydroxypregna-5,7-diene; $11=5 Z, 7 E-3 \beta$-hydroxy9,10-secopregna-5,7,10(19)trien-20-one; $12=5 Z, 7 E-3 \beta, 11 \alpha-$ or $-\beta$-dihydroxy- $9,10-$ secopregna-5,7,10(19)trien-20-one; $13=5 Z$, $7 E$-3, $17 \beta$-dihydroxy-9, 10 -secopregna$5,7,10(19)$ trien-20-one; $14=5 Z, 7 E-3, \beta, 21$ dihydroxy-9, 10-secopregna-5,7,10(19) trien-20-one; $15=5 Z, 7 E-3 \beta, 17 \beta, 21$-trihydroxy-9,10-secopregna-5,7,10(19)trien-20one; $16=5 Z, 7 E-3 \beta, 11 \alpha-$ or $11 \beta, 21$-trihydroxy-9,10-secopregna-5,7,10(19)trien-20one; $17=5 Z, 7 E-3 \beta, 11 \alpha$ - or $11 \beta, 17$-trihydroxy-9,10-secopregna-5,7,10(19)trien-20one; $18=5 Z, 7 E-3 \beta, 11 \alpha$ - or $\beta, 17 \beta, 21$-tetrahydroxy-9,10-secopregna-5,7,10(19) trien20 -one; $19=5 Z, 7 E-3 \beta, 11 \alpha$ - or $\beta$-dihydroxy-9, 10-secopregna-5,7,10(19)triene. Reprinted from Slominski et al. [27], with permission of Blackwell Publishing (copyright owner).
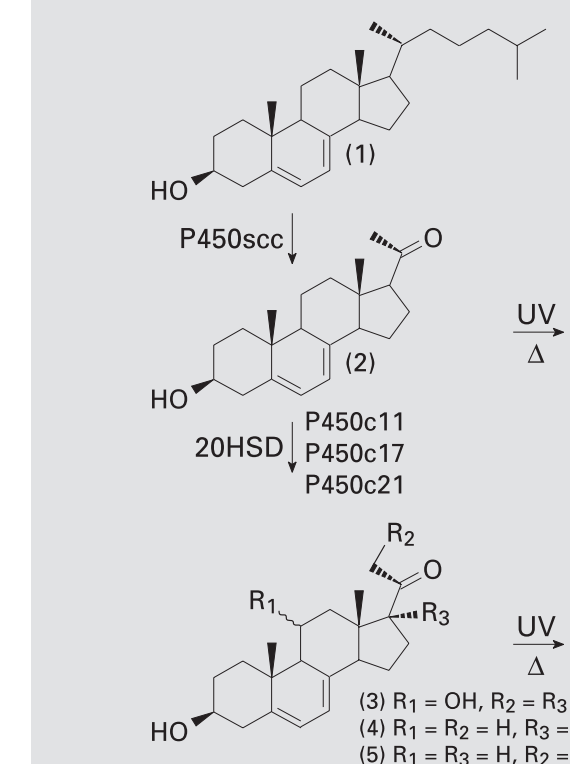

$\mathrm{R}_{2}$

$\mathrm{R}_{2}$

Y $Y 0$

$\underset{\Delta}{\longrightarrow} R_{3}$

(3) $\mathrm{R}_{1}=\mathrm{OH}, \mathrm{R}_{2}=\mathrm{R}_{3}=\mathrm{H}$

(4) $R_{1}=R_{2}=H, R_{3}=O H$ (5) $\mathrm{R}_{1}=\mathrm{R}_{3}=\mathrm{H}, \mathrm{R}_{2}=\mathrm{OH}$ (6) $\mathrm{R}_{1}=\mathrm{H}, \mathrm{R}_{2}=\mathrm{R}_{3}=\mathrm{OH}$ (7) $\mathrm{R}_{1}=\mathrm{R}_{2}=\mathrm{OH}, \mathrm{R}_{3}=\mathrm{H}$ (8) $R_{1}=R_{3}=O H, R_{2}=H$ (9) $R_{1}=R_{2}=R_{3}=O H$

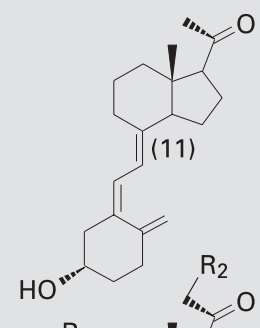

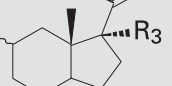
HO*

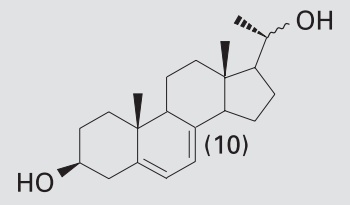

$\underset{\Delta}{\stackrel{U V}{\longrightarrow}}$

(12) $\mathrm{R}_{1}=\mathrm{OH}, \mathrm{R}_{2}=\mathrm{R}_{3}=\mathrm{H}$ (13) $R_{1}=R_{2}=H, R_{3}=O H$ (14) $R_{1}=R_{3}=H, R_{2}=O H$ (15) $\mathrm{R}_{1}=\mathrm{H}, \mathrm{R}_{2}=\mathrm{R}_{3}=\mathrm{OH}$ (16) $R_{1}=R_{2}=O H, R_{3}=H$ (17) $\mathrm{R}_{1}=\mathrm{R}_{3}=\mathrm{OH}, \mathrm{R}_{2}=\mathrm{H}$ (18) $R_{1}=R_{2}=R_{3}=O H$

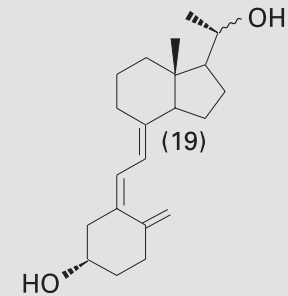

Thus, we have found that incubation of normal epidermal melanocytes and dermal fibroblasts with $\mathrm{CRH}$ triggers the functional cascade structured hierarchically along the same algorithm as in the HPA axis: $\mathrm{CRH}$ activates $\mathrm{CRH}$ receptor 1, stimulates cAMP accumulation and increases POMC gene expression and production of ACTH. This effect is absent in keratinocytes. Melanocytes respond to $\mathrm{CRH}$ and $\mathrm{ACTH}$ with enhanced production of cortisol and corticosterone, which is abolished by POMC gene silencing or by the potent $\mathrm{CRH}$ receptor 1 antagonist antalarmine [45]. Fibroblasts respond to $\mathrm{CRH}$ and ACTH with enhanced production of corticosterone but not cortisol, with ACTH being a more potent stimulator [46]. Thus, melanocytes and fibroblasts but not keratinocytes display a CRH-led system organized similarly to that operating at the systemic level. In case of fibroblasts, it diverges from the central organization in its distal step, where corticosterone, instead of cortisol, is the main ste- roid being stimulated by $\mathrm{CRH}$ and $\mathrm{ACTH}$ [46]. This pattern defines a fractal nature in the response to stress with analogous activation sequences at the single-cell and whole-body levels. Independently, the team from Dr. Paus' laboratory has found that CRH stimulates ACTH and cortisol production in human hair follicles maintained in organ culture in vitro [47].

\section{Steroidogenesis}

The skin is known to synthesize or metabolize androgens or estrogens as well as to serve as a target for those steroid hormones [9, 23, 24, 28]. In fact in postmenopausal women, the skin with subcutaneous adipose tissue is the major producer of estrogens for systemic use.

In addition, over the last decade evidence has accumulated for the cutaneous synthesis of corticosteroids [1]. Thus, the skin expresses both the genes involved in the synthesis of adrenal corticosteroids and their enzymati- 
cally active protein products [1,25-28]. The functional activities of these enzymes (including adrenodoxin, adrenodoxin reductase, $\mathrm{P} 450 \mathrm{scc}, \mathrm{P} 450 \mathrm{c} 17$ and $\mathrm{P} 450 \mathrm{c} 21$ ) have been clearly demonstrated in skin extracts and cultured cells [25, 27, 48]. In vivo, metabolism of progesterone to deoxycorticosterone (DOC) and corticosterone was documented in cultured melanoma cells [49], and to DOC and corticosterone-like products in rat skin [50]. Finally, we were able to detect production of corticosterone and cortisol in human dermal fibroblasts and epidermal melanocytes [45, 46]. Cortisol chemical identity was confirmed by liquid chromatography/mass spectrometry [45]. Immortalized keratinocytes are also steroidogenically active (they exhibit a high catalytic rate for the metabolism of progesterone), although they neither transform progesterone to cortisol nor DOC to ${ }^{18} \mathrm{OH}-\mathrm{DOC}$ or corticosterone [51]. In $\mathrm{HaCaT}$ keratinocytes, exogenously added DOC is transformed to not only 5-dihydroDOC, but also to a number of additional species that include TH-DOC, 6-hydroxy-TH-DOC, $3 \alpha \Delta^{5}-21-\mathrm{OH}-$ pregnenolone and $3 \beta \Delta^{5}-21-\mathrm{OH}$-pregnenolone, $3 \alpha \Delta^{4}-21$ $\mathrm{OH}$-pregnenolone and 6-hydroxydihydro-DOC [51]. Therefore, we suggested a pattern of steroid-converting activity in human keratinocytes characterized by progressive metabolism mediated by $5 \alpha$-reductase, $6 \alpha$-hydroxylase, and $3 \alpha / \beta$-hydroxysteroid dehydrogenase and reverse $\Delta^{4}$ - $\Delta^{5}$-isomerase enzymes [51]. These differences between keratinocytes, melanocytes and fibroblasts would correspond to cell-type-restricted functional differences between different structural compartments of the skin.

\section{Secosteroidogenesis}

Experimental evidence has recently uncovered that the cytochrome P450scc system can efficiently use substrates other than the classical cholesterol molecules [27, 52]. Thus, it can cleave the side chain of 7-dehydrocholesterol (7-DHC) to produce 7-dehydropregnenolone (7DHP; with reaction kinetic similar to the cholesterol conversion to pregnenolone) and also hydroxylates vitamin $\mathrm{D}_{3}\left(\right.$ vitD $\left._{3}\right)$, however with lower efficiency. This pathway may provide, for example, the explanation for the humoral increase in 7-DHP and its hydroxymetabolites when there is excessive accumulation of 7-DHC, e.g. the Smith-Lemli-Opitz syndrome (SLOS); thereby, the pathway may be active in vivo and result in hydroxylation of 7-DHP by classical steroidogenic enzymes, at least under pathological conditions $[53,54]$. Since in the skin the unsaturated sterol B ring of 7-DHC is prone to breakage by UVB photons absorbed in the skin producing vit $\mathrm{D}_{3}[55$, 56], analogous photolytic effects on 7-DHP and its hy- droxymetabolites could generate other vitD-like (vitDL) derivatives [27]. In fact, this could explain the lack of elevation in vitD ${ }_{3}$ levels in spite of 7-DHC tissue accumulation in SLOS and its associated photosensitivity syndrome. Therefore, we proposed that the skin expresses novel steroidogenic/secosteroidogenic pathways with the potential to generate large numbers of new biologically active products (fig. 5) [27]. On the local level, skin, being an important repository of 7-DHC and an expression site for the functional P450scc system, would produce at least 7-DHP, which would in turn become a substrate for further conversions. Because of the comparatively low activity of P450sce, this intrinsic cutaneous pathway would elicit mostly intra-, auto- or paracrine modes under physiological conditions [27]. However, under pathological conditions such as SLOS, UVB-light-induced conversions exclusive for the skin might proceed with substrates derived from the systemic circulation (5,7-steroidal dienes) to generate vitDL compounds. In comparison with P450scc activity on vitD, a possibility becomes apparent of a new potential site for peripheral (skin) modification of vitD $\mathrm{D}_{3}$ bioactivity (this could also take place in the adrenal tissue which expresses high levels of P450scc). Thus, this novel pathway could generate a number of molecules with structures determined by the local type and activity of the steroidogenic system, as well as the access to UV light (UVB) photons (fig. 5) [27].

Within the context above, the skin presents the unique constellation of having simultaneously available the enzymatic system potential substrates, e.g. cholesterol, 7DHC and vitD $\mathrm{D}_{3}$, and UVB light exposure providing an excellent model for the systematic investigation of the expression and contribution of each component in the proposed steroidogenic/secosteroidogenic pathway. Among the expected products would be 7-DHP together with its hydroxyderivatives generated by the action of classic steroidogenic enzymes. The resulting unsaturated B ring compounds could become targets for UVB-induced photolysis to produce vitDL substances; vitD 3 itself could serve as an alternate substrate for the same P450scc system. Under pathological conditions such as SLOS, UVB-light-induced conversions in the skin might utilize substrates derived from the systemic circulation (5,7-steroidal dienes) to generate vitDL compounds that perhaps may be responsible for the extreme photosensitivity in these patients. Alternatively, they may represent a new class of hormones/neurohormones at the peripheral or central level. Of note, the profound behavioral abnormalities of SLOS are thought to result from either production of $\Delta^{7}$ unsaturated neurosteroid-like com- 
pounds [57], to which we may add vitDL compounds crossing the blood-brain barrier. The new P450scc activity on vitD adds a new potential site for the modification of vitD $\mathrm{D}_{3}$ bioactivity. Obviously, this could take place in heavy-expressing P450scc tissues such as the adrenal or in peripheral sites like the skin. Thus, the proposed pathway could potentially generate a number of biologically active substances, by either creating new functions or by repressing existing activities (inactivating vit $\mathrm{D}_{3}$ ). Furthermore, local selective modulation of the enzymatic activity transforming 7-DHC to 7-DHP and subsequently to hydroxy-7-DHP derivatives and/or vitDL compounds could represent a specific mechanism to affect the phenotype of cells of ectodermal, endodermal or mesenchymal origin. This would include modification in the availability of vitD ${ }_{3}$. We envision the action of the generated compounds as involving activation of specific receptors or of nonreceptor regulatory proteins. As it is generally accepted that biological substances produced in the body should have their own receptors or binding sites on regulatory proteins, it is contemplated that there must be natural cellular or extracellular proteins with high affinity for these compounds. It is perhaps the binding to such proteins that would modify the metabolic phenotype or metabolic status of the cell or organ targeted. Thus, these compounds may become therapeutic agents or adjuvant therapeutics for the treatment of skin diseases or simply for cosmetic purposes. In addition, these compounds could act as modifiers of action of other biologically active substances. In fact, the therapeutic relevance of corticosteroids as first-line agents in the management of inflammatory skin disorders and autoimmune processes deserves special attention. Thus, novel concepts introduced by this project include the local generation of a new family of steroids/secosteroids (fig. 5), their integral participation in tissue homeostasis and their potential role in the pathogenesis of inflammatory dermatoses or of autoimmune processes originating in the skin [27].

\section{Serotoninergic/Melatoninergic System}

Using molecular, biochemical and chemical techniques, we have recently uncovered cutaneous expression of the biochemical machinery involved in the sequential transformation of $L$-tryptophan to serotonin and melato$\operatorname{nin}[21,22,58-63]$. This included detection of genes and protein expression with actual enzymatic activities for tryptophan hydroxylase, serotonin $\mathrm{N}$-acetyltransferase and hydroxyindole-O-methyltransferase (HIOMT) in the skin and skin cells [21, 58-62]. Indications for in vivo synthesis of serotonin and its metabolism to N-acetylserotonin and potentially melatonin in skin cells were also obtained in organ and cell culture systems [60, 63].

Production of $\mathrm{N}$-acetylserotonin in the C57/BL6 mouse deserves separate attention [64], because this mouse strain has been proposed as a natural melatonin 'knockdown' because of a genetic defect in arylalkylamine $\mathrm{N}$-acetyltransferase (AANAT) function [65]. Indeed, C57/BL6 mice have undetectable production of melatonin in the pineal gland and very low to undetectable concentrations in plasma [65]. Surprisingly, significant production of melatonin has been reported in bone-marrow-derived cells $[66,67]$. When we performed tests to probe the expression of a melatoninergic system in the skin of C57/BL6 mice, we confirmed that the C57/BL6 produced aberrant AANAT isoforms [64]. Despite the lack of expression of the correct AANAT enzyme in the C57/BL6 mouse, extracts of skin nevertheless transformed serotonin to $\mathrm{N}$-acetylserotonin and acetylated tryptamine, however with a lower efficiency than for serotonin; identity of the reaction products was confirmed by liquid chromatography/mass spectrometry [64]. Our detailed biochemical analyses demonstrated that the C57/BL6 mouse skin did acetylate serotonin to N-acetylserotonin in a reaction mediated by an enzyme different from conventional AANAT, most likely NAT-1 [64]. This provided the biochemical explanation for the finding of melatonin production in C57/BL6 mice at selected extracranial sites expressing HIOMT [66], which may use $\mathrm{N}$-acetylserotonin substrate originated in the skin and delivered through the systemic circulation for production of melatonin. However, we must emphasize that our studies did exclude corporal skin of the C57/ BL6 mouse as a site of melatonin production, at least at detectable levels by techniques used in our laboratories [64].

Both serotonin and melatonin are also degradated in the skin. Thus, monoamine oxidase can deaminate serotonin, followed by the oxidation or reduction of the resultant 5-hydroxyindole acetaldehyde to 5-hydroxyindole acetic acid and 5-hydroxytryptophol as demonstrated by liquid chromatography/mass spectrometry analyses of mouse skin extracts [62-64]. We have also obtained evidence for melatonin metabolism in the skin with some identified products including 5-methoxyindole acetic acid, 5-methoxytryptophol or hydroxymelatonin [22, 63]. Thus, based on our findings and information available in the literature we have proposed that the following serotoninergic/melatoninergic pathway including their biodegradation is operating in the skin (fig. 6). 


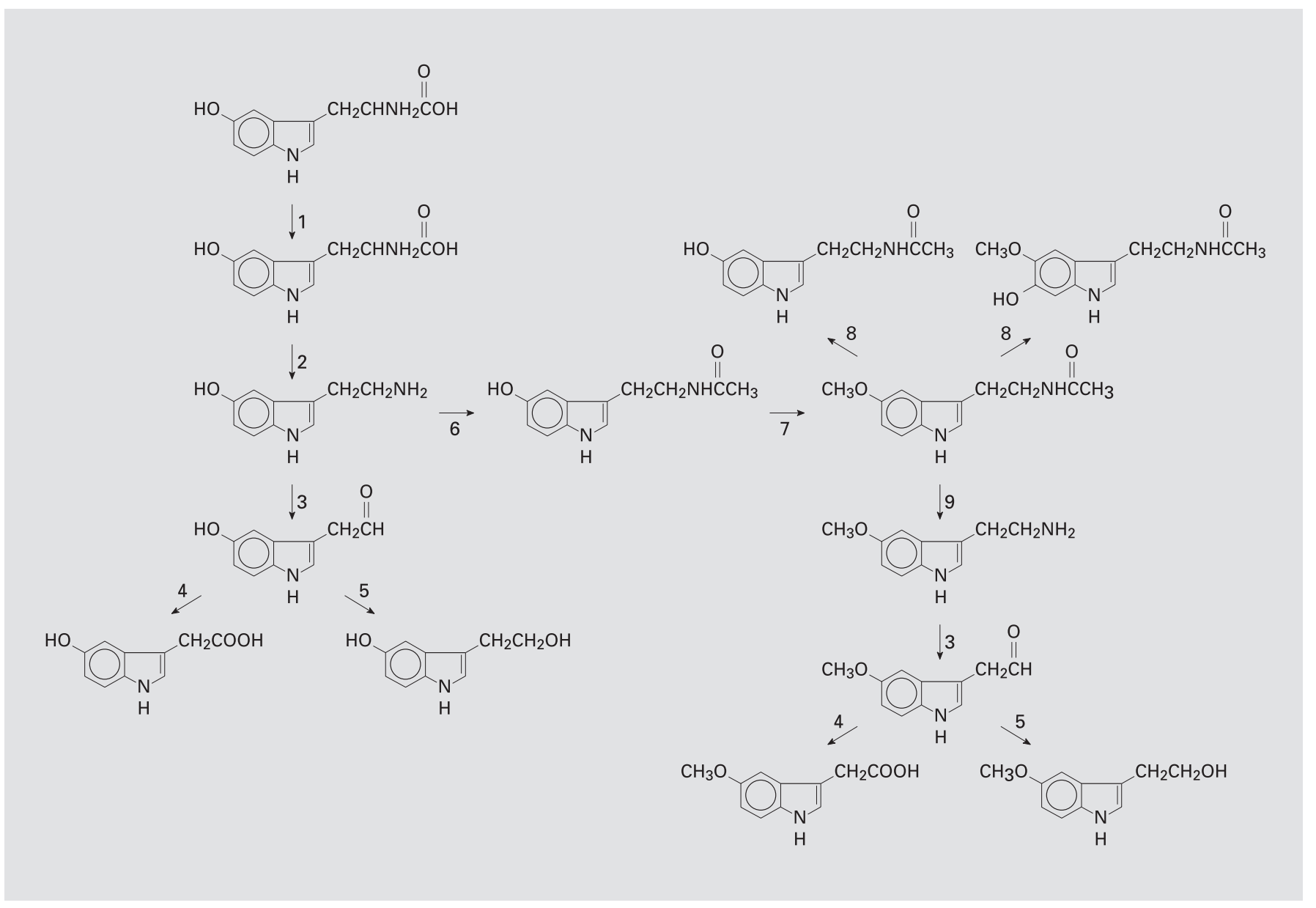

Fig. 6. Proposed model of the serotoninergic/melatoninergic pathway in the mammalian skin. Tryptophan hydroxylase (1); AAD (2); monoamine oxidase (3); aldehyde dehydrogenase (4); alcohol dehydrogenase (5); AANAT (6); HIOMT (7); cytochrome P-450 (8); melatonin deacetylase (9). Reprinted from Slominski et al. [22], with permission of FASEB publications (copyright owner).

Moreover, receptors for serotonin and melatonin are expressed in human keratinocytes, melanocytes and fibroblasts, and these mediate phenotypic actions on cellular proliferation and differentiation [68]. Expression of melatonin and serotonin receptors and phenotypic effects of melatonin and serotonin were also reported for rodent skin [22, 69-71]. In addition, melatonin exerts receptorindependent effects including the activation of pathways protective of oxidative stress and the modification of cellular metabolism. While serotonin is known to have several roles in skin, e.g. pro-edema, vasodilatory, pro-inflammatory and pruritogenic, melatonin has been experimentally implicated in hair growth cycling, pigmentation physiology and melanoma control [22]. Therefore, we proposed that cutaneous serotoninergic/melatoninergic system(s) should have considerable selectivity of action to facilitate intra-, auto- or paracrine mechanisms that define and influence skin function in a highly compartmentalized manner [22]. The action of such a system would target epidermal, pigmentary, dermal and adnexal functions. Our hypothesis is that this novel system operating in the skin acts to preserve physical integrity of the organ and maintain its homeostasis. It would be activated by environmental stresses or internal dyshomeostatic stimuli, and would counteract or buffer their damaging effect. Implicit in this highly mechanistic hypothesis are paracrine/autocrine and/or intracrine mechanisms of action for melatonin or serotonin. The resulting phenotypic effects would then depend on in situ availability, dynamically regulated by local production and degrada- 
tion of this hormone, and accessibility and permissibility of cellular targets for bioregulation. The net effect of the concerted actions would be the maintenance of an efficient epidermal biological barrier hence involving highly organized differentiation of epidermal keratinocytes, hair follicle activity (particularly important in fury animals), fibroblast activity (builds and regulates structure of the dermis) and pigmentary activity (important in social communication and protection against solar radiation). The comparative significance of the proposed model is embodied in its contribution to the elucidation of mechanisms involved in the skin response to stressors (environmental and endogenous). It is interesting that whereas skin exposure to noxious stimuli is continuous, the pineal gland (a known site of melatonin production) is insulated from the external environment that results in discontinuous activation related to the circadian rhythm. Thus, it is likely that this discrepancy in activation timing would be associated with regulation of skin melatonin production independent of circadian activation. Instead, environmental stressors (e.g. solar radiation) in human skin or local intrinsic factors (e.g. stage of hair follicle cycle) in rodent skin may be important regulatory factors. Such functional dissociation does not exclude a role for the cAMP signal transduction pathway in the regulation of the cutaneous melatoninergic system, as it is at the central level, with the pathway being evolutionarily conserved between pineal gland, retina and skin.

\section{Hypothalamic-Pituitary-Thyroid Axis}

Since the skin is commonly affected in thyroid diseases [72], but the mechanism for this association is still unclear, we tested the additional cutaneous expression of mediators operating in the hypothalamic-pituitary-thyroid axis [29]. We found significant expression of the thyroid-stimulating hormone receptor (TSH-R) mRNA in cultured keratinocytes, epidermal melanocytes and melanoma cells, and the TSH-R was found to be functionally active in cAMP signal assays. TSH-R-expressing cells also expressed the sodium iodide symporter and thyroglobulin genes [29]. Deiodinases $\mathrm{D}_{2}$ and $\mathrm{D}_{3}$ (mainly $\mathrm{D}_{2}$ ) genes were expressed in the skin biopsy specimens, and in the majority of human epidermal and dermal cells cultured in vitro. This was accompanied by selective expression of the TSH $\beta$ mRNA, and expression of thyroid-releasing hormone gene was minimal being restricted to dermal and follicular papilla fibroblasts, neonatal but not adult keratinocytes and melanoma cells [29]. Interestingly thyroid-releasing hormone receptor mRNA was not detected in most of the samples, indicating that thyroid-releasing hormone would act on a different receptor, most likely MC-1R [73]. We have also proposed that expression of functional TSH-R in the skin may have significant physiological and pathological consequences, particularly in autoimmune conditions associated with the production of stimulating antibodies against the TSH-R [29]. Specifically we postulated that some forms of Graves' disease could be due to an autoimmune response directed primarily against a cutaneous TSH-R antigen; this could result from abnormal expression of MHC proteins and abnormal exposure of TSH-R antigen to immune cells, in response to exposure to environmental insults, e.g. solar radiation or skin infections [29].

\section{Functional Organization of the Cutaneous Neuroendocrine System}

These newly recognized hormonal expressions in the skin are performed by cells that appear to be compartmentally arranged into units comprising epidermal or dermal with adnexal structures (fig. 1-3). Since these structures concomitantly produce hormones and express the corresponding receptors, the predominant mechanisms of interaction must be auto- and paracrine in nature. Cutaneous nerve fibers provide additional levels of communication through anterograde or retrograde transmission of impulses with release of neuropeptides at epidermal or dermal levels (fig. 2). The true endocrine component of the cutaneous neuroendocrine system is represented by those humoral signals that can directly enter the circulation (fig. 4).

Furthermore, the cutaneous neural signaling system may also potentially activate pathways in the central nervous system, when changes in the skin physicochemical environment generated by physical, chemical or biological trauma or local disease processes are transmitted via the spinal cord to the brain (fig. 2, 4). Alternatively, the information can be transmitted via the spinal cord directly to other organs to regulate their local or secretory function, thus indirectly regulating global homeostasis (fig. 4). The challenge for future research is to define how the absorbance of the solar radiation energy by the skin can affect the central nervous system or function of other organs through neural transmission originating in the skin (fig. 4). 


\section{Concluding Remarks}

To summarize, when stressed the skin can generate signals to produce rapid (neural) or slow (humoral) responses at the local or systemic levels (fig. 4). These responses are likely addressed at counteracting the environmental insults and/or modulating optimally the homeostatic adaptation mechanisms. Thus, the uncovering of this system of multidirectional communications between skin, endocrine, immune and central nervous systems as well as other internal organs suggests the existence of a new layer for the regulation of global homeostasis (fig. 4). This would be represented by the skin acting as a sensor for external or internal disturbances and by the cutaneous neuroendocrine system acting as an effector/producer of humoral or neural signals sent to local or distant coordinating or executory centers.

\section{Acknowledgement}

The author thanks numerous scientists and trainees for their intellectual and experimental contributions to the concepts presented above. The most important contributors are Dr. J. Wortsman and Drs. G. Ermak, M. Foecking, S. Gaudet, C. Gomez-Sanchez, L. Kohn, T. Luger, J. Mazurkiewicz, R. Paus, J. Pawelek, A. Pisarchik, I. Semak, J. Stewart, T. Sweatman, D.J. Tobin, R. Tuckey, E. Wei, B. Zbytek and J. Zjawiony. The project was supported in part by NIH grant No. AR047079.

\section{References}

1 Slominski A, Wortsman J: Neuroendocrinology of the skin. Endocr Rev 2000;21:457487.

2 Slominski A, Pawelek J: Animals under the sun: Effects of UV radiation on mammalian skin. Clin Dermatol 1998;16:503-515.

3 Bos J: Skin Immune System (SIS), ed 2. Boca Raton, CRC Press, 1997.

-4 Luger T, Paus R, Slominski A, Lipton J: Cutaneous neuromodulation: The proopiomelanocortin system. Ann NY Acad Sci 1999;885: $1-479$.

5 Slominski A, Tobin DJ, Shibahara S, Wortsman J: Melanin pigmentation in mammalian skin and its hormonal regulation. Physiol Rev 2004;84:1155-1228.

-6 Stenn KS, Paus R: Controls of hair follicle cycling. Physiol Rev 2001;81:449-494.

7 Bohm M, Zouboulis CC: Dermato-endocrinology - An exciting area of skin research with promising perspectives. Exp Dermatol 2004; 13(suppl 4):3-4.

-8 Elias P, Ahn S, Brown B, Crumrine D, Feingold KR: Origin of the epidermal calcium gradient: Regulation by barrier status and role of active vs passive mechanisms. J Invest Dermatol 2002;119:1269-1274.

-9 Zouboulis CC, Bohm M: Neuroendocrine regulation of sebocytes - A pathogenetic link between stress and acne. Exp Dermatol 2004; 13(suppl 4):31-35.

10 Slominski A, Wortsman J, Plonka PM, Schallreuter KU, Paus R, Tobin DJ: Hair follicle pigmentation. J Invest Dermatol 2005; 124:1321.

11 Slominski A, Wortsman J: Self-regulated endocrine systems in the skin. Minerva Endocrinol 2003;28:135-143.

-12 Slominski A, Mihm M: Potential mechanism of skin response to stress. Int J Dermatol 1996; 35:849-851.
3 Slominski A, Paus R, Wortsman J: On the potential role of proopiomelanocortin in skin physiology and pathology. Mol Cell Endocrinol 1993;93:C1-C6.

14 Slominski A, Wortsman J, Luger T, Paus R, Solomon S: Corticotropin releasing hormone and proopiomelanocortin involvement in the cutaneous response to stress. Physiol Rev 2000;80:979-1020.

15 Slominski A, Wortsman J, Pisarchik A, et al: Cutaneous expression of corticotropin-releasing hormone $(\mathrm{CRH})$, urocortin, and $\mathrm{CRH}$ receptors. Faseb J 2001;15:1678-1693.

16 Zouboulis CC, Seltmann H, Hiroi N, et al: Corticotropin-releasing hormone: An autocrine hormone that promotes lipogenesis in human sebocytes. Proc Natl Acad Sci USA 2002;99: 7148-7153.

17 Grando SA: Biological functions of keratinocyte cholinergic receptors. J Invest Dermatol Symp Proc 1997;2:41-48.

18 Grando SA, Horton RM: The keratinocyte cholinergic system with acetylcholine as an epidermal cytotransmitter. Curr Opin Dermatol 1997; 1997:462-468.

19 Schallreuter KU, Lemke KR, Pittelkow MR, Wood JM, Korner C, Malik R: Catecholamines in human keratinocyte differentiation. J Invest Dermatol 1995;104:953-957.

20 Gillbro JM, Marles LK, Hibberts NA, Schallreuter KU: Autocrine catecholamine biosynthesis and the beta-adrenoceptor signal promote pigmentation in human epidermal melanocytes. J Invest Dermatol 2004;123: 346-353.

21 Slominski A, Pisarchik A, Semak I, et al: Serotoninergic and melatoninergic systems are fully expressed in human skin. Faseb J 2002;16: 896-898.

22 Slominski A, Wortsman J, Tobin DJ: The cutaneous serotoninergic/melatoninergic system: Securing a place under the sun. Faseb J 2005; 19:176-194.
23 Labrie F, Luu-The V, Labrie C, Pelletier G, ElAlfy M: Intracrinology and the skin. Horm Res 2000; 54:218-229.

24 Zouboulis CC, Degitz K: Androgen action on human skin - From basic research to clinical significance. Exp Dermatol 2004;13(suppl 4):5-10.

25 Thiboutot D, Jabara S, McAllister JM, et al: Human skin is a steroidogenic tissue: Steroidogenic enzymes and cofactors are expressed in epidermis, normal sebocytes, and an immortalized sebocyte cell line (SEB-1). J Invest Dermatol 2003;120:905-914.

26 Slominski A, Ermak G, Mihm M: ACTH receptor, CYP11A1, CYP17 and CYP21A2 genes are expressed in skin. J Clin Endocrinol Metab 1996;81:2746-2749.

27 Slominski A, Zjawiony J, Wortsman J, et al: A novel pathway for sequential transformation of 7-dehydrocholesterol and expression of the P450scc system in mammalian skin. Eur J Biochem 2004;271:4178-4188, 2004.

28 Chen W, Thiboutot D, Zouboulis CC: Cutaneous androgen metabolism: Basic research and clinical perspectives. J Invest Dermatol 2002; 119:992-1007.

29 Slominski A, Wortsman J, Kohn L, et al: Expression of hypothalamic-pituitary-thyroid axis related genes in the human skin. J Invest Dermatol 2002;119:1449-1455.

30 Chrousos GP: The hypothalamic-pituitary-adrenal axis and immune-mediated inflammation. N Engl J Med 1995;332:1351-1362.

31 Aguilera G: Corticotropin releasing hormone, receptor regulation and the stress response. Trends Endocrinol Metab 1998;9:329-336.

32 Grammatopoulos DK, Chrousos GP: Functional characteristics of $\mathrm{CRH}$ receptors and potential clinical applications of CRH-receptor antagonists. Trends Endocrinol Metab 2002; 13:436-444. 
- 33 Smith AI, Funder JW: Proopiomelanocortin processing in the pituitary, central nervous system, and peripheral tissues. Endocr Rev 1988; 9:159-179.

- 34 Slominski A, Pisarchik A, Tobin DJ, Mazurkiewicz JE, Wortsman J: Differential expression of a cutaneous corticotropin-releasing hormone system. Endocrinology 2004;145: 941-950.

- 35 Slominski A, Roloff B, Curry J, Dahiya M, Szczesniewski A, Wortsman J: The skin produces urocortin. J Clin Endocrinol Metab 2000;85:815-823.

- 36 Slominski A, Szczesniewski A, Wortsman J: Liquid chromatography-mass spectrometry detection of corticotropin-releasing hormone and proopiomelanocortin-derived peptides in human skin. J Clin Endocrinol Metab 2000;85: 3582-3588.

37 Slominski A, Baker J, Ermak G, Chakraborty A, Pawelek J: UVB stimulates production of corticotropin releasing factor (CRF) by human melanocytes. FEBS Lett 1996;399:175-176.

- 38 Slominski A, Paus R, Mazurkiewicz J: Proopiomelanocortin expression in the skin during induced hair growth in mice. Experientia 1992;48:50-54.

39 Slominski A, Ermak G, Hwang J, Chakraborty A, Mazurkiewicz J, Mihm M: Proopiomelanocortin, corticotropin releasing hormone and corticotropin releasing hormone receptor genes are expressed in human skin. FEBS Lett 1995; 374:113-116.

-40 Zbytek B, Pfeffer LM, Slominski AT: Corticotropin-releasing hormone stimulates NF-kap$\mathrm{paB}$ in human epidermal keratinocytes. J Endocrinol 2004;181:R1-R7.

-41 Zbytek B, Slominski, A: Corticotropin-releasing hormone induces keratinocyte differentiation in the adult human epidermis. J Cell Physiol 2005;203:118-126.

-42 Slominski AT, Botchkarev V, Choudhry M, et al: Cutaneous expression of $\mathrm{CRH}$ and $\mathrm{CRH}-\mathrm{R}$ : Is there a 'skin stress response system'? Ann NY Acad Sci 1999;885:287-311.

43 Slominski A, Wortsman J, Linton E, Pisarchik A, Zbytek B: The skin as a model for the immunomodulatory effects of corticotropin-releasing hormone; in Schaefer M, Stein C (eds): Mind over Matter - Regulation of Peripheral Inflammation by the CNS. Basel, Birkhaeuser, 2003, pp 149-176.

-44 Slominski A, Heasley D, Ermak G, Mazurkiewicz JE, Baker J, Carlson A: Expression of proopiomelanocortin (POMC) derived melanocyte stimulating hormone (MSH) and ACTH peptides in skin of basal cell carcinoma patients. Hum Pathol 1999;30:208-215.

-45 Slominski A, Zbytek B, Szczesniewski A, et al: $\mathrm{CRH}$ stimulation of corticosteroids production in melanocytes is mediated by ACTH. Am J Physiol Endocrinol Metab 2005;288:E701E706.
46 Slominski A, Zbytek B, Senak I, Sweatman T, Wortsman J: CRH stimulates POMC activity and corticosterone production in dermal fibroblasts. J Neuroimmunol 2005;162:97-102.

47 Ito N, Ito T, Kromminga A, Bettermann A, Takigawa M, Kees F, Straub RH, Paus R: Human hair follicles display a functional equivalent of the hypothalamic-pituitary-adrenal (HPA) axis and synthesize cortisol. FASEB J, in press.

48 Rogoff D, Gomez-Sanchez CE, Foecking MF, Wortsman J, Slominski A: Steroidogenesis in the human skin: 21-Hydroxylation in cultured keratinocytes. J Steroid Biochem Mol Biol 2001;78:77-81.

-49 Slominski A, Gomez-Sanchez CE, Foecking MF, Wortsman J: Metabolism of progesterone to DOC, corticosterone and $18 \mathrm{OHDOC}$ in cultured human melanoma cells. FEBS Lett 1999; 455:364-366.

50 Slominski A, Gomez-Sanchez C, Foecking MF, Wortsman J: Active steroidogenesis in the normal rat skin. Biochim Biophys Acta 2000; 1474:1-4.

51 Slominski A, Wortsman J, Foecking MF, Shackleton CH, Gomez-Sanchez CE, Szczesniewski A: Gas chromatography/mass spectrometry characterization of corticosteroid metabolism in human immortalized keratinocytes. J Invest Dermatol 2002;118:310-315.

-52 Guryev O, Carvalho RA, Usanov S, Gilep A, Estabrook RW: A pathway for the metabolism of vitamin $\mathrm{D}_{3}$ : Unique hydroxylated metabolites formed during catalysis with cytochrome P450scc (CYP11A1). Proc Natl Acad Sci USA 2003; 100:14754-14759.

-53 Shackleton C, Roitman E, Guo LW, Wilson WK, Porter FD: Identification of 7(8) and 8(9) unsaturated adrenal steroid metabolites produced by patients with 7-dehydrosterol-delta7reductase deficiency (Smith-Lemli-Opitz syndrome). J Steroid Biochem Mol Biol 2002;82: 225-232.

54 Shackleton CH, Roitman E, Kelley R: Neonatal urinary steroids in Smith-Lemli-Opitz syndrome associated with 7-dehydrocholesterol reductase deficiency. Steroids 1999;64:481490.

-55 Tian XQ, Holick MF: A liposomal model that mimics the cutaneous production of vitamin $\mathrm{D}_{3}$ : Studies of the mechanism of the membrane-enhanced thermal isomerization of previtamin $\mathrm{D}_{3}$ to vitamin $\mathrm{D}_{3}$. J Biol Chem 1999; 274:4174-4179.

56 Holick MF: Vitamin D: A millenium perspective. J Cell Biochem 2003;88:296-307.

57 Marcos J, Guo LW, Wilson WK, Porter FD, Shackleton C: The implications of 7-dehydrosterol-7-reductase deficiency (Smith-LemliOpitz syndrome) to neurosteroid production. Steroids 2004;69:51-60.

58 Slominski A, Pisarchik A, Semak I, Sweatman T, Szczesniewski A, Wortsman J: Serotoninergic system in hamster skin. J Invest Dermatol 2002;119:934-942.
59 Slominski A, Pisarchik A, Johansson O, et al: Tryptophan hydroxylase (TPH) expression in human skin cells. Biochim Biophys Acta 2003; 1639:80-86.

60 Slominski A, Semak I, Pisarchik A, Sweatman T, Szczesniewski A, Worstman J: Conversion of $L$-tryptophan to serotonin and melatonin in melanoma cells. FEBS Lett 2002;511:102106.

61 Gaudet SJ, Slominski A, Etminan M, Pruski D, Paus R, Namboordiri MAA: Identification and characterization of two isozymic forms of arylamine N-acetyltransferase in Syrian hamster skin. J Invest Dermatol 1993;101:660665 .

62 Semak I, Korik E, Naumova M, Wortsman J, Slominski A: Serotonin metabolism in rat skin: Characterization by liquid chromatographymass spectrometry. Arch Biochem Biophys 2004:421:61-66.

63 Slominski A, Baker J, Rosano T, et al: Metabolism of serotonin to N-acetylserotonin, melatonin, and 5-methoxytryptamine in hamster skin culture. J Biol Chem 1996;271:12281-12286.

64 Slominski A, Pisarchik A, Semak I, Sweatman $\mathrm{T}$, Wortsman J: Characterization of the serotoninergic system in the C57BL/6 mouse skin. Eur J Biochem 2003;270:3335-3344.

65 Roseboom PH, Namboodiri MA, Zimonjic DB, et al: Natural melatonin 'knockdown' in C57BL/6J mice: Rare mechanism truncates serotonin N-acetyltransferase. Brain Res Mol Brain Res 1998;63:189-197.

66 Conti A, Conconi S, Hertens E, Skwarlo-Sonta K, Markowska M, Maestroni JM: Evidence for melatonin synthesis in mouse and human bone marrow cells. J Pineal Res 2000;28:193-202.

67 Reiter RJ: Pineal melatonin: Cell biology of its synthesis and of its physiological interactions. Endocr Rev 1991;12:151-180.

68 Slominski A, Pisarchik A, Zbytek B, Tobin DJ, Kauser S, Wortsman J: Functional activity of serotoninergic and melatoninergic systems expressed in the skin. J Cell Physiol 2003;196: 144-153.

69 Slominski A, Chassalerris N, Mazurkiewicz J, Paus R: Murine skin as a target for melatonin bioregulation. Exp Dermatol 1994;3:45-50.

70 Slominski A, Pruski D: Melatonin inhibits proliferation and melanogenesis in rodent melanoma cells. Exp Cell Res 1993;206:189-294.

71 Slominski A, Pisarchik A, Wortsman J: Expression of genes coding melatonin and serotonin receptors in rodent skin. Biochim Biophys Acta 2004; 1680:67-70.

72 Thiboutot DM: Clinical review 74: Dermatological manifestations of endocrine disorders. J Clin Endocrinol Metab 1995;80:30823087.

73 Slominski A, Plonka PM, Pisarchik A, et al: Preservation of eumelanin hair pigmentation in proopiomelanocortin-deficient mice on a non-agouti (a/a) genetic background. Endocrinology 2005;146:1245-1253. 